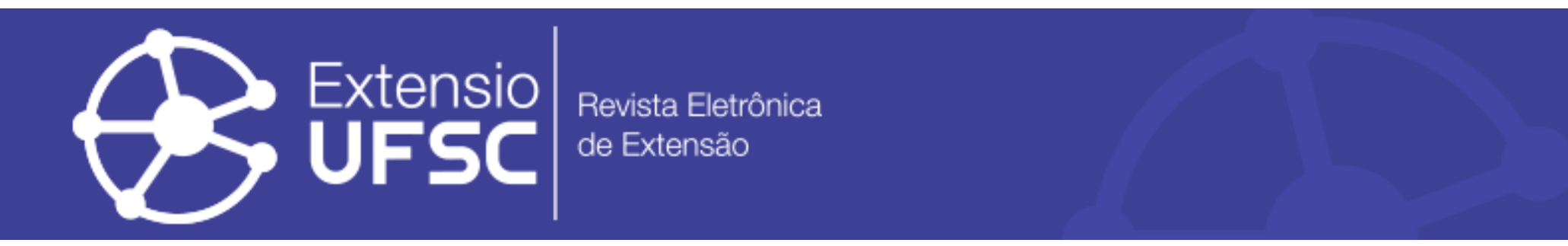

\title{
A PRÁTICA EXTENSIONISTA EM UMA UNIVERSIDADE PÚBLICA FEDERAL
}

\author{
Eliane Fernandes Pietrovski \\ Universidade Tecnológica Federal do Paraná \\ eliane@utfpr.edu.br \\ Márcia de Souza Bronzeri \\ Universidade Estadual do Norte do Paraná \\ mbronzeri@uenp.edu.br
}

\author{
João Carlos da Cunha \\ Universidade Positivo \\ jccunhaisat@gmail.com \\ Dálcio Roberto dos Reis \\ Universidade Positivo \\ dalcio.reis@gmail.com
}

Laíze Márcia Porto Alegre Universidade Tecnológica Federal do Paraná laizepa@utfpr.edu.br

\begin{abstract}
Resumo
A universidade tem importante papel, tanto pela formação profissional quanto pessoal dos indivíduos, contribuindo para a sociedade. $\mathrm{O}$ ensino, a pesquisa e a extensão, são a base para disseminar o conhecimento, integrando as diversas formas de percepção e análise, internalizando o saber e estimulando a investigação. O objetivo desta pesquisa é apresentar uma análise do programa de extensão na Universidade Tecnológica Federal do Paraná. A pesquisa é exploratória e descritiva, com dados primários e secundários, coletados no período de maio a junho de 2015. O procedimento de análise é qualitativo e quantitativo. Os principais resultados destacam que as ações de extensão associam o saber teórico e prático, no processo interdisciplinar da universidade voltada para a sociedade. A dinâmica da extensão, assim como os seus mecanismos de facilitação é de conhecimento e objeto de discussão e destacam o papel da universidade como participante do desenvolvimento regional integrado.
\end{abstract}

Palavras-chave: Extensão Universitária. Ensino-Pesquisa-Extensão. Universidade-Sociedade.

\section{THE EXTENSIONIST PRACTICE AT A FEDERAL PUBLIC UNIVERSITY}

\begin{abstract}
The university has an important role, both for the professional and personal training of individuals, contributing to society. Teaching, research and extension are the basis for disseminating knowledge, integrating the various forms of perception and analysis, internalizing knowledge and stimulating research. The objective of this research is to present an analysis of the extension program at the Federal University of Technology - Paraná. The research is exploratory and descriptive, with primary and secondary data, collected from May to June 2015. The analysis procedure is qualitative and quantitative. The main results highlight that the extension actions associate theoretical and practical knowledge in the universiy's interdisciplinary process focused on society. The extension's dynamics, as well as its facilitation mechanisms, are knowledge and object of discussion and highlight the university's role as a participant in integrated regional development.
\end{abstract}

Keywords: University Extension. Education-Research-Extension. University-Society.

\section{LA PRÁCTICA EXTENSIONISTA EN UNA UNIVERSIDAD PÚBLICA FEDERAL}

\section{Resumen}

La universidad tiene un importante papel por la formación profesional y personal de los individuos, contribuyendo a la sociedade. La enseñanza, la investigación y la extensión, son la base para diseminar el conocimiento integrando las diversas formas de percepción y análisis, internalizando el saber y estimulando la investigación. El objetivo de esta investigación es presentar un análisis de la experiencia del programa de extensión en la Universidade Tecnológica Federal do Paraná. La investigación es exploratoria y descriptiva, con datos primarios y secundarios, recogidos en el período de mayo a junio de 2015. El procedimiento de análisis es cualitativo y cuantitativo. Los principales resultados destacan que acciones de extensión asocian el saber teórico y práctico, en el proceso interdisciplinario de la universidad orientada a la sociedad. La dinámica de la extensión, así como sus mecanismos de facilitación es de conocimiento y objeto de discusión y destacan el papel de la universidad como participante del desarrollo regional integrado.

Palabras clave: Extensión Universitaria. Enseñanza-Investigación-Extensión. Universidade-Sociedade. 


\section{INTRODUÇÃO}

A extensão universitária é considerada como um processo educativo, cultural e científico. Partindo dessa abordagem, esta pesquisa contextualiza a extensão universitária como um processo chave do tripé ensino, pesquisa e extensão. Apoia-se no referencial proposto pelo Plano Nacional de Extensão Universitária, realizado no período de 2000/2001 (FORPROEX, 2001), pelo Fórum de Pró-Reitores de Extensão das Universidades Públicas Brasileiras (Forproex) e pela Secretaria de Educação Superior do Ministério de Educação (SESu/MEC).

Segundo a abordagem apoiada na participação da universidade no processo interdisciplinar que articula a teoria/prática voltada para a sociedade, procura-se nesta pesquisa destacar os desafios para que este processo se realize e atinja os objetivos propostos. Neste contexto, surge a questão de pesquisa que norteará esta investigação empírica: Como a extensão se articula com o ensino e pesquisa universitária em uma instituição pública multicâmpus?

Foi analisado o caso de uma universidade multicâmpus que desenvolve e incentiva em suas práticas organizacionais, a relação com o setor empresarial, com o setor público e demais organizações da sociedade. Este estudo enfoca, portanto, as experiências da Universidade Tecnológica Federal do Paraná (UTFPR) em sua atuação como agente do desenvolvimento regional, buscando a articulação dos agentes locais e a superação das restrições tecnológicas, econômicas e sociais presentes nas realidades regionais.

A UTFPR foi transformada a partir do Centro Federal de Educação Tecnológica do Paraná (Cefet-PR), o qual originou-se da Escola de Aprendizes Artífices, fundada em 1909. Com ampla abrangência territorial, a UTFPR atua em treze câmpus no Estado do Paraná - Brasil, nas cidades: Apucarana, Campo Mourão, Cornélio Procópio, Curitiba, Dois Vizinhos, Francisco Beltrão, Guarapuava, Londrina, Medianeira, Pato Branco, Ponta Grossa, Santa Helena e Toledo.

A presente pesquisa tem como objetivo geral: apresentar uma análise longitudinal da experiência da extensão em uma universidade pública, depois de transformada, em 2005, de Cefet-PR para UTFPR. E tem como objetivos específicos:

- Apresentar o contexto organizacional das práticas de extensão na UTFPR e sua estrutura multicâmpus;

- Identificar os mecanismos utilizados pelos programas, projetos e demais ações de extensão bem como a articulação entre ensino e pesquisa na UTFPR;

- Avaliar a coerência entre a legislação, a demanda regional e o o resultado da UTFPR;

- Propor recomendações para melhoria dos processos e práticas de extensão na UTFPR. 
A prática extensionista em uma universidade pública federal

Justifica-se o desenvolvimento da pesquisa, na dimensão prática, por apresentar a extensão como um processo fundamental para articular o tripé ensino, pesquisa e extensão, no qual a universidade desempenha relevante papel junto à sociedade, na formação de profissionais melhor preparados para atender às constantes mudanças e desenvolver as inovações a serem adotadas pelas organizações. Formação essa que ultrapassa os limites da sala de aula e passa pela vivência de situações e desafios organizacionais, sendo que a gestão da universidade deve contemplar também o ensino a pesquisa e a extensão, numa "concepção ampliada de gestão universitária”, defendida por Sampaio e Laniado (2009). Do ponto de vista teórico, o presente estudo é importante pelo interesse e relevância que o tema tem despertado não somente na academia como também nas demais organizações governamentais e não governamentais que realizam a interface com a extensão no ensino superior, por meio de parcerias.

\section{QUADRO TEÓRICO DE REFERÊNCIA}

A extensão é uma forma de participação da universidade na interação com a sociedade, ao democratizar conhecimentos produzidos pela pesquisa e compartilhados com o ensino, com relação de troca e compartilhamento de conhecimentos entre a universidade e a sociedade. Desta forma, a importância do papel da extensão na universidade perpassa a obrigatoriedade de cumprimento da lei para inciativas de planejamento e execução de atividades de extensão que respeitem os valores e culturas da comunidade (SILVA, 1997).

Nessa trajetória, a extensão universitária teve, inclusive, a tarefa de mudar a caracterização de suas atividades de assistencialistas (CABRAL, 2012; CARBONARI; PEREIRA, 2007; RODRIGUES, 2008; SANTOS, 2012) para um mecanismo da aprendizagem (GOULART, 2004; MACIEL, 2010; NUNES; SILVA, 2011), pautado no pensamento crítico (RODRIGUES, 2008), um elo entre a universidade e a sociedade (ARAUJO et al., 1998; CABRAL, 2012; CARBONARI E PEREIRA, 2007; NUNES; SILVA, 2011; SANTOS, 2012).

No contexto da extensão universitária, há que se considerar a interdependência entre o ensino, pesquisa e extensão. Silva (1997) afirma que a pesquisa corresponde ao oxigênio que revitaliza e aprimora o ensino, caso contrário corre o risco de estagnação. A extensão corresponde à ponte que leva os conhecimentos à comunidade por meio de aplicações práticas para ser efetivada, alimentadas pelos conteúdos, pelas contribuições dos alunos e professores. A extensão prescinde da pesquisa para diagnosticar e solucionar problemas da comunidade, buscando sempre a atualização. A pesquisa prescinde do ensino e da extensão para ampliar seu universo de atuação, para novas descobertas, para difundir e aplicar sua produção, bem como para conduzir aos novos rumos do saber científico. 
Entretanto, apesar da interação e indissociabilidade do ensino, da pesquisa e da extensão, conforme princípio estabelecido no Artigo 207 da Constituição Federal (BRASIL, 1988), a atividade de extensão ainda requer atenção e esclarecimentos quanto à sua importância dentro do contexto da formação no ensino superior, sendo necessário, para isso, o estabelecimento de um equilíbrio entre as três áreas, para que se atinja a qualidade e o sucesso esperado dos profissionais formados pelas universidades (SILVA, 1997).

Conforme ressaltam Araujo et al. (1998, p.178):

A indissociabilidade só será alcançada mediante uma ação intencional da universidade capaz de superar o paradigma de ensino reprodutivo, fruto do modelo positivista, avançando para novas formas de produção do conhecimento, fundamentadas no modelo humanista - dialógico, cuja construção, certamente, envolverá de forma integrada a pesquisa e a extensão.

Para reforçar a indissociabilidade e alcançar os objetivos definidos no Plano Nacional de Extensão Universitária (FORPROEX, 2001), há que se considerar as mudanças que levam a pensar e projetar a universidade com a função acadêmica, social e articuladora, relativas à fundamentação em bases teórico-metodológicas, promovendo a organização da sociedade por meio da interligação do saber e do fazer (SERRANO, 2014). Mudanças essas que podem também envolver inovações tecnológicas (KING, 1999) que atendem a uma demanda da sociedade, inclusive de facilidade de acesso, o que pode representar oportunidades (KING; BOEHLJE, 2000), bem como novos desafios.

Nesta construção do panorama da extensão universitária, destaca-se a sua importância no ensino e pesquisa, bem como na formação integral, no aspecto profissional e social do aluno.

\section{MATERIAIS E MÉTODOS}

Para responder à questão problema, foi realizada uma investigação empírica na UTFPR. O método aplicado para elaboração do presente trabalho foi uma pesquisa exploratória e descritiva, com abordagem qualitativa e quantitativa. As fontes de coleta dos dados são primárias e secundárias. O método de coleta de dados primários foi composto por entrevista e questionário, realizados no período de maio a junho de 2015 e os dados secundários foram coletados por meio de documentos e relatórios de gestão.

Para a pesquisa utilizou-se o método de estudo de caso, com um corte seccional, porém com retrospectiva considerando a transformação desde 2005, de Cefet-PR para UTFPR. Segundo Yin (2015) o estudo de caso permite que o pesquisador faça um levantamento dos eventos causais ao longo do tempo. A metodologia utilizada na pesquisa apresentou três eixos básicos: 


\section{A prática extensionista em uma universidade pública federal}

investigação empírica; organização dos dados; proposição de melhoria dos processos e práticas de extensão.

O público alvo da pesquisa, num total de 51 pessoas, compreendeu os gestores vinculados à extensão: Diretoria de Extensão (Dirext); Diretoria de Relações Empresariais e Comunitárias (Direc) e Departamento de Extensão (Depex) dos 13 câmpus da UTFPR. Todas as diretorias e respectivos departamentos de extensão estão vinculados à Pró-Reitoria de Relações Empresariais e Comunitárias (Prorec). Deste público, 22 responderam à pesquisa, representando uma amostra de aproximadamente 43,14\%.

Para a primeira etapa da pesquisa, foi feito um levantamento, por meio da coleta de dados secundários, das atividades de extensão na UTFPR, via documentos e relatórios de gestão. $\mathrm{Na}$ segunda etapa foi realizada a coleta de dados primários, no período de maio a junho de 2015, por meio de questionário enviado, via web, aos responsáveis pelas atividades de extensão nas Direc, nos 13 câmpus da UTFPR e aos gestores da Dirext e Prorec. Nessa etapa também foi realizada entrevista semiestruturada com um dos integrantes da equipe da Dirext, cuja diretoria é responsável por todas as ações extensão na UTFPR. O protocolo de entrevista resultou em 12 perguntas.

Os dados secundários foram utilizados para complementar os dados primários, possibilitando a triangulação desses, consoante ao objetivo da pesquisa e apoiaram-se: no referencial proposto pelo Plano Nacional de Extensão Universitária (FORPROEX, 2001); e nos relatórios de gestão e documentos de extensão da UTFPR.

$\mathrm{Na}$ coleta e análise de dados buscou-se responder à indagação que definiu o problema a ser resolvido pela pesquisa, destacando como se apresenta a extensão universitária em uma instituição pública, partindo dos seguintes pressupostos:

- As ações de extensão precisam estar articuladas com o ensino e a pesquisa nas universidades.

- A extensão não tem alcançado resultados expressivos para evidenciar a articulação entre o ensino e a pesquisa.

- Os programas, projetos e ações de extensão somados às atividades de ensino e pesquisa colaboram para o processo de transferência para todos os setores da sociedade.

- Os mecanismos de apoio à extensão promovem efetivamente as ações de extensão de forma abrangente.

A presente pesquisa limita suas observações devido às características específicas quanto à abrangência e quanto aos dados coletados, que se restringiram aos gestores vinculados às ações de extensão na Prorec, Dirext e nas Direc nos câmpus da UTFPR. 


\section{RESULTADOS E ANÁLISES}

A UTFPR apresenta como instrumentos de gestão, em seu ambiente acadêmico, as ações de extensão, apoiando e subsidiando os projetos de sua comunidade discente, docente e de técnicos-administrativos com o objetivo de estimular a interação entre a universidade e a sociedade.

Segundo o Relatório de Gestão (UTFPR, 2014, p.343)

A UTFPR tem buscado cada vez mais atuar de maneira socialmente responsável, principalmente a partir de 2005, quando da sua transformação em universidade. Desta forma, seus câmpus têm buscado se envolver em ações sociais de modo sistemático. Com o panorama derivado das atividades sociais desenvolvidas na UTFPR, pode-se ter uma perspectiva real da interação Academia/Sociedade, o que contribui de maneira efetiva para o direcionamento de investimentos em áreas que impliquem um maior retorno social e determinação de condições para o desenvolvimento de indicadores de Responsabilidade Social.

As ações de extensão (UTFPR, 2012, p.7) estão vinculadas à Pró-Reitoria de Relações Empresariais e Comunitárias (Prorec), por meio da Diretoria de Extensão (Dirext). Nos câmpus da UTFPR a operacionalização das ações de extensão (UTFPR, 2012, p.8) está vinculada à Direc, por meio do: Departamento de Apoio e Projetos Tecnológicos (Depet); Departamento de Estágios e Cursos de Qualificação Profissional (Depec); Departamento de Relações Interinstitucionais (Derint) e Departamento de Extensão (Depex), dando destaque aos Núcleos (FIGURA 1), cujas ações dos programas e projetos de extensão correspondem às áreas temáticas propostas no Plano Nacional de Extensão Universitária (FORPROEX, 2001).

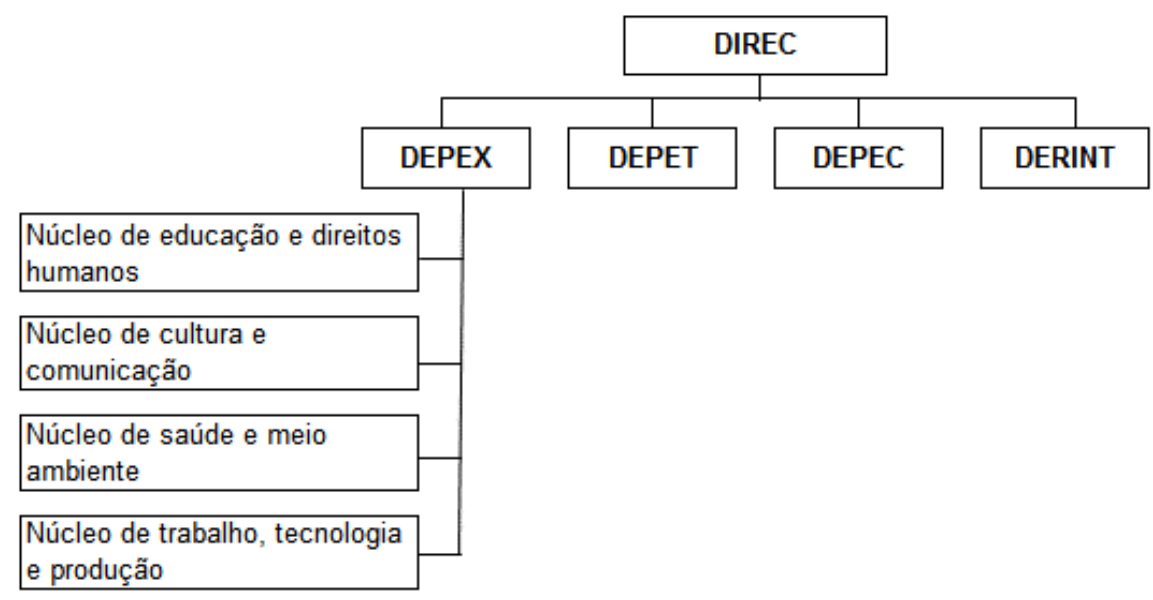

Figura 1 - Organograma da Extensão em cada câmpus da UTFPR Fonte: Guia da Extensão (UTFPR, 2012:9). 


\section{A prática extensionista em uma universidade pública federal}

Os dados coletados permitem uma análise, primeiramente, no contexto organizacional das práticas de extensão na UTFPR, apresentando os mecanismos de gestão em seu ambiente acadêmico, por meio das ações de extensão, as quais apoiam e subsidiam os projetos de sua comunidade discente, docente e de técnicos-administrativos.

As modalidades de extensão, de acordo com o Forproex (2001), são desenvolvidas por meio de: programas, projetos, eventos, cursos e apoio tecnológico (UTFPR, 2015). O Gráfico 1 apresenta alguns Indicadores de Extensão, selecionados para esta pesquisa.



Gráfico 1 - Indicadores de Extensão Fonte: Dados da pesquisa.

Os programas e projetos passaram a ser registrados de forma efetiva a partir de 2007. Como pode ser observado no Gráfico 1, de 2009 para 2010 ocorreu um avanço e que de 2012 para 2013 apresentou um incremento expressivo de 385 para 1439 (aumento de mais de 270\%). Já em 2014 apresentou uma redução de cerca de 30\% (de 1439 para 1050) em relação a 2013. Esta redução se justifica pelo fato de ocorrer, a partir de 2013, o ajuste no registro dos dados pela adoção de uma ferramenta com base em uma planilha eletrônica na internet, que pode ser atualizada em tempo real. Dentre os projetos, o entrevistado destacou o trabalho que vem sendo desenvolvido em uma comunidade de Corumbataí do Sul, próxima ao Câmpus de Campo Mourão, com que "visam desde a parte ambiental, da parte de agronomia, da parte de educação, capacitação dessa comunidade", com integração do ensino, pesquisa e extensão. 


\section{A prática extensionista em uma universidade pública federal}

Em 2007 houve o maior número de eventos (1252), em parte justificado pelo acréscimo de mais três câmpus na UTFPR, com seus eventos correspondentes. E naquele ano o evento marcante na instituição e que continuou nos anos seguintes, foi a Exposição da Universidade Tecnológica (ExpoUT), realizada anualmente, ocorrendo simultaneamente em todos os câmpus, durante a qual a comunidade pode conhecer as principais realizações da instituição e dos seus cursos. Além disso, empresas parceiras participam para que empresários prospectem oportunidades nas demonstrações de projetos originados a partir de Trabalhos de Conclusão de Curso. Em 2013 houve uma queda significativa no número de eventos, porém a discussão do Relatório de Gestão (UTFPR, 2013) aponta que, embora o número tenha reduzido, o número de pessoas envolvidas triplicou.

Além dos dados apresentados no Gráfico 1, também destacam-se os projetos e apoios tecnológicos que são disponibilizados para os diferentes segmentos da sociedade, a partir de competências identificadas nas pessoas e infraestruturas disponíveis em cada câmpus. Os projetos podem ser desenvolvidos em parcerias ou com recursos pagos pelos demandantes do setor empresarial.

Portanto, quanto aos mecanismos utilizados pelos programas, projetos e demais ações de extensão na UTFPR, as modalidades são abrangentes e desenvolvidas de forma integral pelos: programas com característica de ação continuada; projetos com ação específica, com duração prévia; projeto e apoio tecnológico com ações realizadas pelas demanda da comunidade externa ou interna e contínua; curso de qualificação profissional de acordo com demandas internas e externas; eventos de extensão que envolvem a comunidade interna e externa; egressos com ações de acompanhamento em sua carreira profissional; visitas técnicas e gerenciais na busca de interação com o setor empresarial e ainda, a pesquisa e produção em relação às ações de extensão, atuando de forma articulada, viabilizando a relação transformadora entre universidade e sociedade, de acordo com o Plano Nacional de Extensão Universitária (FORPROEX, 2001), desempenhando a função necessária para a ligação entre a universidade e a sociedade, indicada por Araujo et al. (1998), Cabral (2012), Carbonari e Pereira (2007), Nunes e Silva (2011) e Santos (2012).

Em se tratando de assistencialismo, segundo o entrevistado, [...] esse não é o foco da extensão, que visa contribuir para o desenvolvimento da comunidade, principalmente local, sendo que o assistencialismo não é suficiente para transformar a realidade dessas comunidades que cercam a universidade, então a proposta é levar o conhecimento adquirido em sala de aula (ensino) para comunidades externas, identificando problemas e oportunidades (pesquisa), para aplicação prática de ações visando a transformação da comunidade (extensão). Pelos dados 


\section{A prática extensionista em uma universidade pública federal}

obtidos nos questionários (GRÁFICO 2), a maioria dos respondentes (63\%) discorda plenamente da extensão na UTFPR ser vista como atividade assistencialista, mas ainda há quem concorda com essa visão.

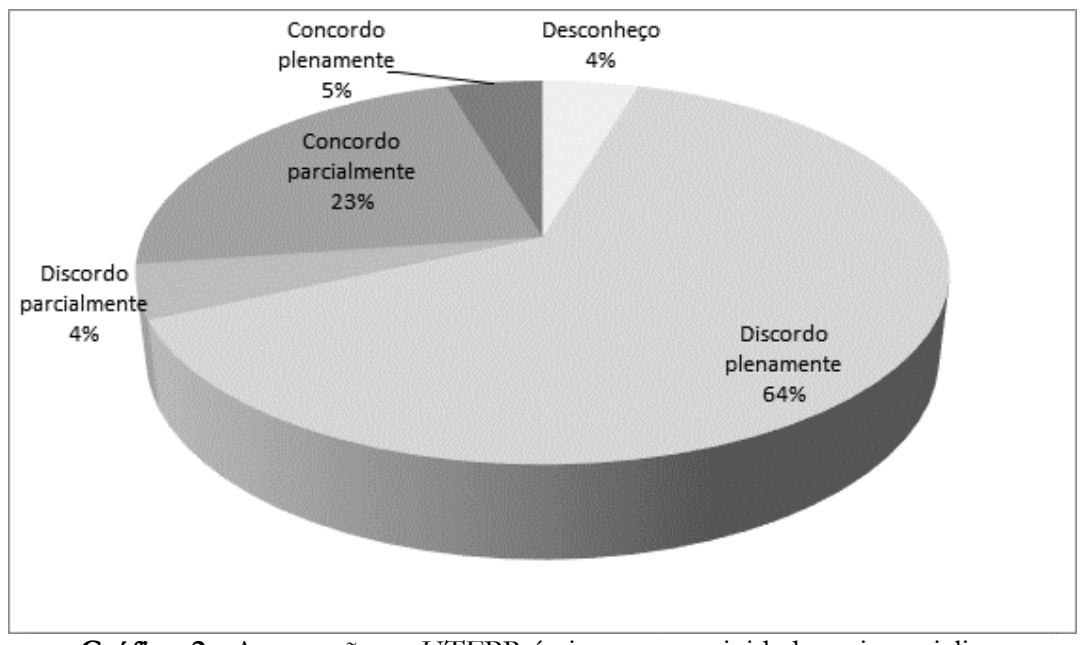

Gráfico 2 - A extensão na UTFPR é vista como atividade assistencialista Fonte: Dados da pesquisa.

Quanto às atividades de extensão estarem integradas às atividades de ensino e pesquisa (GRÁFICO 3), 41\% dos respondentes concordam parcialmente, 32\% concordam plenamente e $27 \%$ discordam parcialmente em que há essa integração.

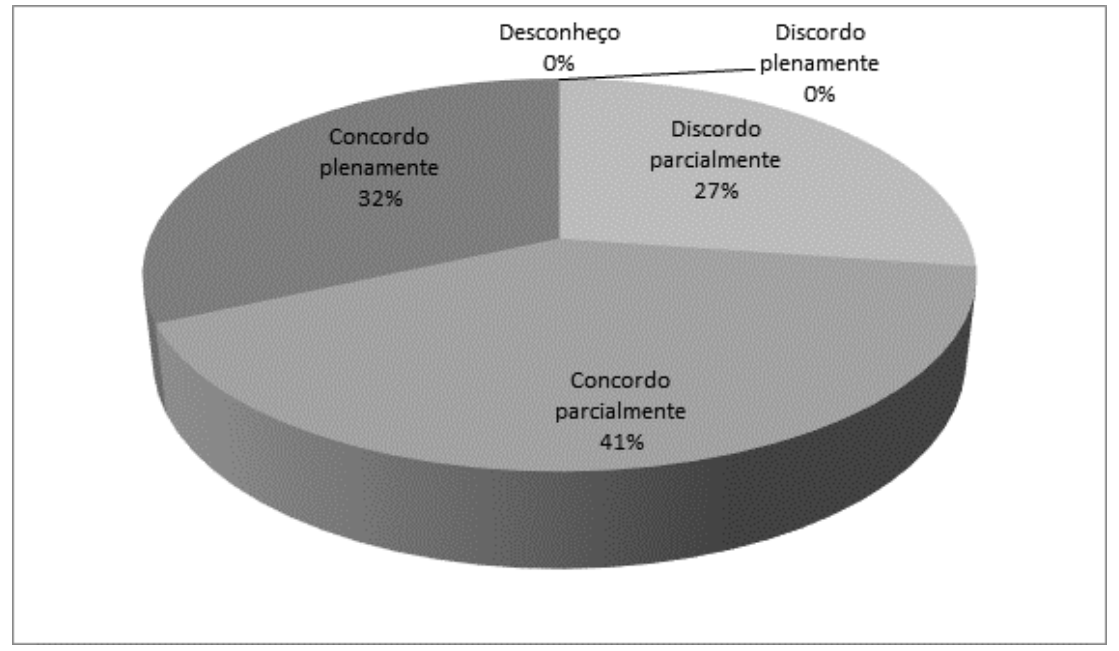

Gráfico 3 - As atividades de extensão são integradas às atividades de ensino e pesquisa Fonte: Dados da pesquisa.

Por meio de análise das ações de extensão pode-se identificar alguns indicativos da indissociabilidade do ensino, pesquisa e extensão, tais como: os projetos e programas de extensão, além dos estágios e ofertas de empregos das empresas cadastradas em um banco on line; os cursos de qualificação profissional; os apoios tecnológicos; a sensibilização e caracterização da 
necessidade de se disseminar a cultura empreendedora pelas ações da Agint, NIT e pelo Proem, atuando nos câmpus da UTFPR.

Ressalta-se, ainda buscando aproximar o tripé ensino, pesquisa e extensão, na demanda regional o Programa de Acompanhamento de Egressos, cujas ações tem como objetivo acompanhar o aluno em sua carreira profissional no setor empreendedor e empresarial, mesmo após ter deixado a universidade; as visitas técnicas e gerenciais que proporcionam a interação da universidade-empresa; e a pesquisa e produção científica, que funcionam também como um mecanismo de aprendizagem (GOULART, 2004; MACIEL, 2010; NUNES; SILVA, 2011), que apresentam em seu bojo as questões sociais e comunitárias.

Também foi possível identificar que a UTFPR incentiva atividades extracurriculares, no que se refere às ações culturais e esportivas, proporcionando, principalmente aos discentes, uma formação plena e humanística. Esta identificação é comprovada nos dados que apontam que alunos, por meio destas ações de extensão, têm a possibilidade de desenvolver relaçõesinterpessoais positivas com a comunidade em que estão inseridos e também reflete a importância da extensão para a sociedade, em seu papel para minimizar diferenças (OROZCO, 2014).

Com a criação do Conselho de Relações Empresariais e Comunitárias (Coemp), a UTFPR confirma sua intenção em discutir e divulgar a extensão universitária como função acadêmica responsável por articular ensino, pesquisa e extensão promovendo a cidadania e a prática da responsabilidade social.

Diante da diversidade de ações, com suas respectivas especificidades, buscou-se verificar o conhecimento dos respondentes quanto à existência de documentos/regulamentos sobre a extensão na UTFPR, sendo que, $82 \%$ dos respondentes concordam plenamente que conhecem e $18 \%$ concordam parcialmente com a afirmativa (GRÁFICO 4).

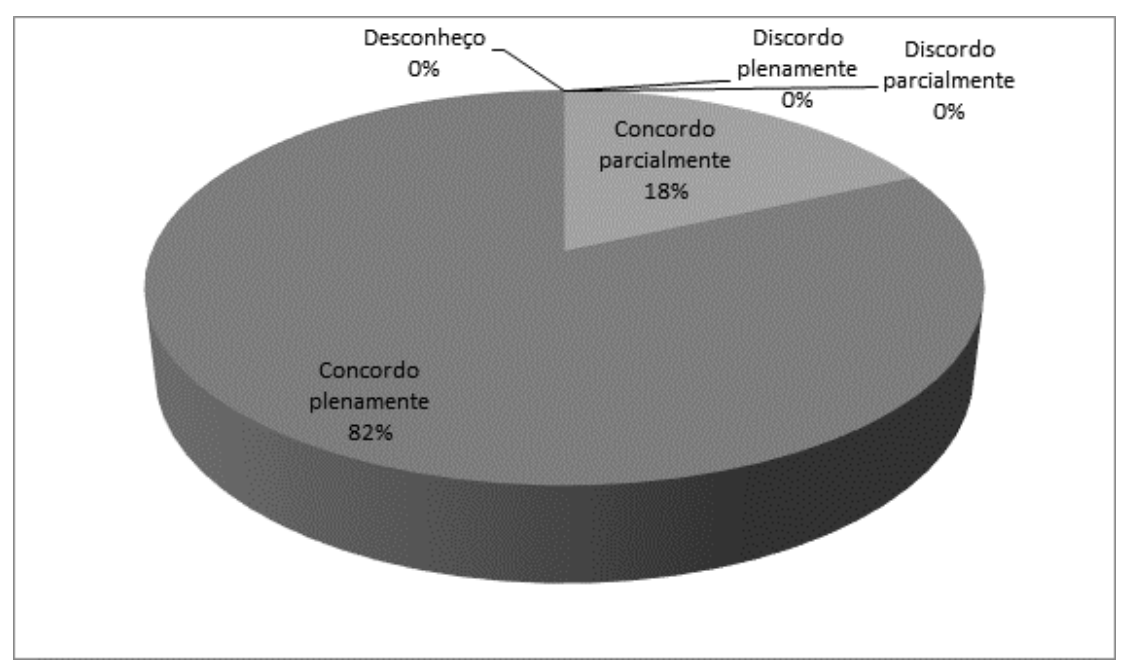

Gráfico 4 - Existem documentos/regulamentos sobre a extensão na UTFPR Fonte: Dados da pesquisa. 


\section{A prática extensionista em uma universidade pública federal}

Além dos mecanismos de gestão que vinculam o ensino, pesquisa e extensão e de outros programas que contam com a participação efetiva de servidores (docentes e técnicosadministrativos) e alunos, o Programa Comunidade Integrada na Multiplicação de Conhecimentos (Cimco), é o programa de extensão institucionalizado nos câmpus, que tem 20 anos de existência completados em setembro de 2016, cujo objetivo é implementar a política social da UTFPR, por meio da definição de diretrizes básicas voltadas para a promoção da qualidade de vida de seus servidores, alunos e comunidade em geral. Outro projeto institucional de extensão, que a UTFPR realiza em parceria desde 2007 com o Ministério da Defesa (Brasil), é o Projeto Rondon o qual tem como propósito promover a integração social e envolve a participação efetiva voluntária dos alunos e professores, com o objetivo de buscar soluções que contribuam para o desenvolvimento sustentável de comunidades carentes.

Internamente os mecanismos de fomentos estão relacionados ao Programa Institucional de Apoio a Ações de Extensão (Proext), por meio de concessão de bolsa de extensão, com recursos próprios da UTFPR, cujo objetivo é viabilizar a participação de alunos e servidores (docentes e técnico-administrativos) da UTFPR na disponibilização de recursos para o desenvolvimento de projetos de extensão e de inovação. Os relatórios de gestão indicam um número crescente de projetos submetidos anualmente, o que é um fator positivo, pois esses têm atendido à demanda da comunidade interna, desenvolvendo ações de extensão para a comunidade externa.

Quanto à existência de mecanismos extensionistas desenvolvidos na UTFPR (GRÁFICO 5), $67 \%$ dos respondentes concordam plenamente, 19\% concordam parcialmente e 14\% discordam parcialmente com a afirmativa. Aliado a esse resultado, pelos dados coletados nos documentos, pode-se inferir que a maioria dos câmpus da UTFPR apresentam esta atividade bem consolidada, angariando credibilidade nos projetos e apoios tecnológicos que fornece. 


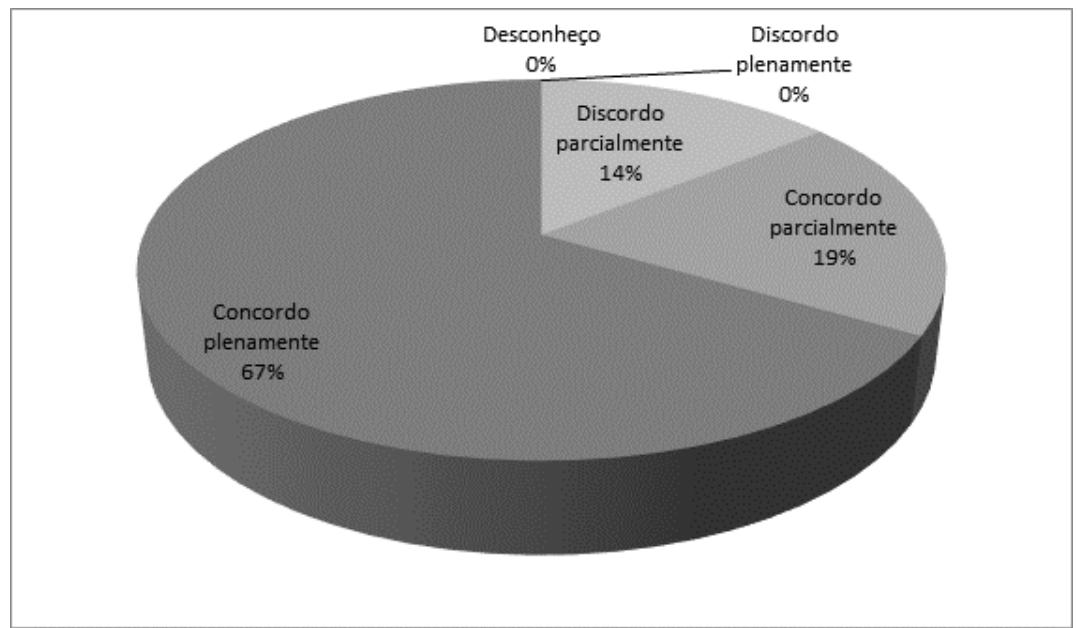

Gráfico 5 - Há mecanismos extensionistas desenvolvidos na UTFPR Fonte: Dados da pesquisa.

Para a institucionalização das atividades de extensão foi criado, em 2010, o Conselho de Relações Empresariais e Comunitárias (Coemp), cujos objetivos de trabalho envolvem as aprovações: de regulamentos relacionados a programas de desenvolvimento social e comunitário; de mecanismos de interação entre universidade-empresa-comunidade; e de regulamento de concessão de bolsas de extensão. Com relação a essa interação universidade-empresacomunidade, $77 \%$ dos respondentes concordam plenamente e $23 \%$ concordam parcialmente que a extensão da UTFPR procura aproximar a universidade com a sociedade (GRÁFICO 6).

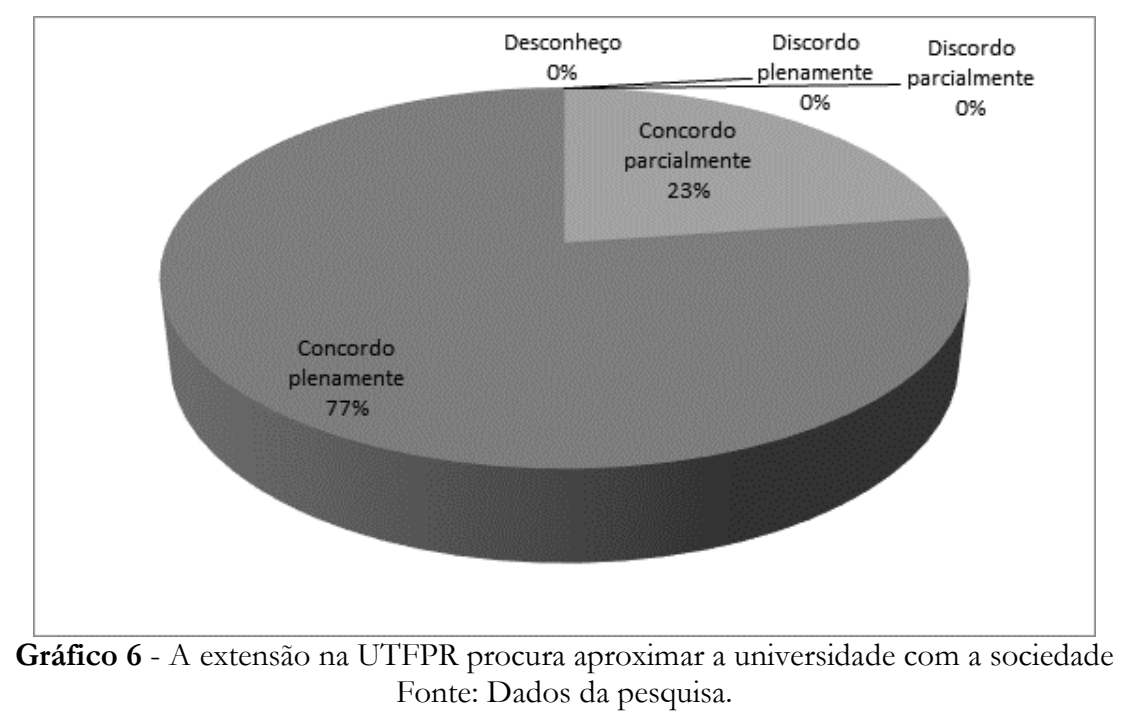

Destaca-se a ação, coordenada pela Dirext, que foi a discussão da estrutura de uma Política Cultural para a UTFPR, aprovada pelo Conselho Universitário (COUNI), em fevereiro de 2017, com a implementação neste mesmo ano. Outro importante trabalho é realizado pelo Comitê de Extensão, o qual é um órgão assessor de caráter deliberativo, com a finalidade de zelar 


\section{A prática extensionista em uma universidade pública federal}

pela qualidade institucional da extensão e incentivar seu desenvolvimento na UTFPR, apoiando e incentivando as ações de extensão.

Em relação à coerência entre a legislação, o resultado da UTFPR e a demanda regional (GRÁFICO 7), 36\% dos respondentes concordam parcialmente que existe coerência, 32\% concordam plenamente, $23 \%$ discordam parcialmente e $9 \%$ desconhecem.

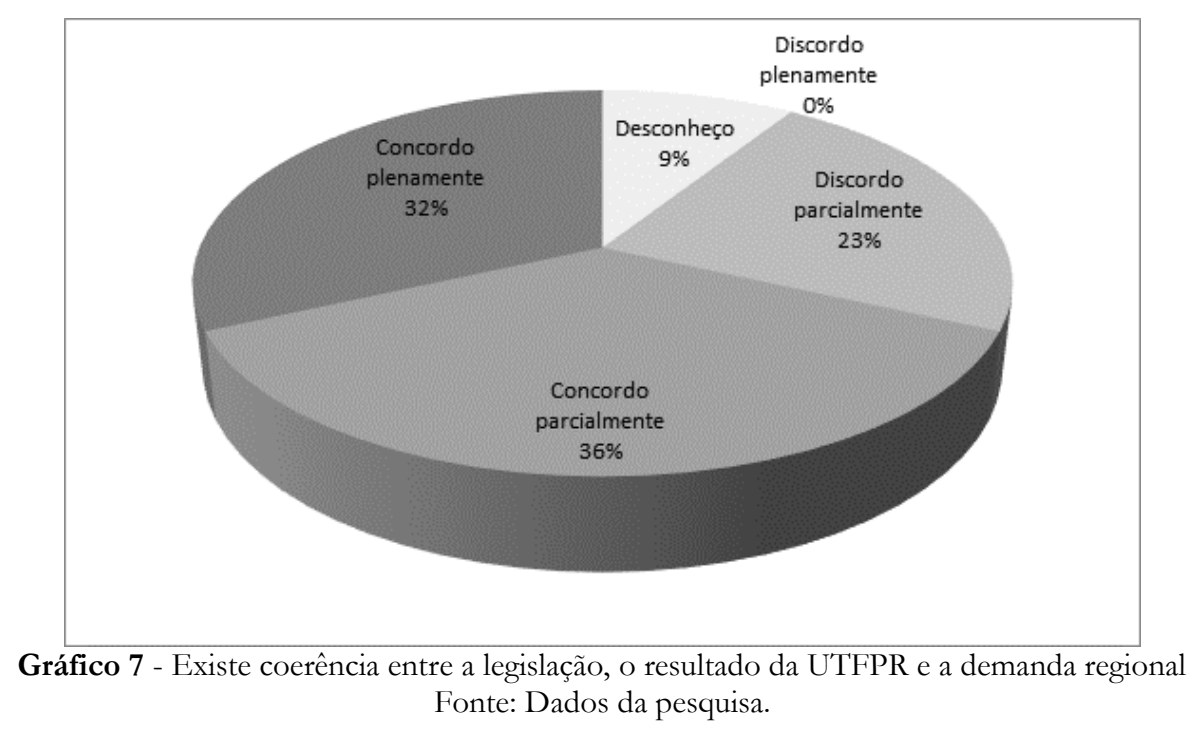

Portanto, considerando a coerência entre a legislação, a demanda regional e o resultado da UTFPR podem-se inferir que as ações específicas de extensão são desenvolvidas pelos Núcleos, separados por áreas de atuação as quais correspondem ao Plano Nacional de Extensão Universitária (FORPROEX, 2001), buscando articular a relação extensionista entre a sociedade e universidade, de forma abrangente, contemplando não somente a ética como também a responsabilidade socioambiental sustentável.

Os documentos regulatórios e a definição de uma política de extensão reafirmam a relação universidade-sociedade, com ações reguladas por demandas regionais de acordo com a localização de seus câmpus em todo o Estado do Paraná, e estão em consonância principalmente com documentos que regem a extensão, de abrangência nacional, como o Plano Nacional de Extensão Universitária (FORPROEX, 2001), conforme propõem os especialistas na literatura (ARAUJO et al., 1998; CABRAL, 2012; CARBONARI E PEREIRA, 2007; NUNES; SILVA, 2011; SANTOS, 2012).

$\mathrm{Na}$ busca para articular as ações de extensão, na relação entre a sociedade e universidade, a UTFPR contempla em sua Política de Extensão a ética, bem como a responsabilidade socioambiental sustentável (UTFPR, 2012). Nesse sentido, segundo as informações fornecidas pelo entrevistado, tem o exemplo do projeto na comunidade de Corumbataí do Sul e também o caso de Pinhais, onde há contribuição de diversos cursos realizando "projetos na área de meio 


\section{A prática extensionista em uma universidade pública federal}

ambiente, na área de arquitetura, na área de design, que eles vão lá e ajudam no desenvolvimento da comunidade, com o cuidado com os rios, as áreas alagadas". Dessa forma, o envolvimento dos alunos nesses projetos de extensão, além de contribuir para o desenvolvimento da região atendida, complementa o ensino, resultando em "profissional formado de uma maneira não só teórica, mas sim prática e de maneira social também”.

A extensão promove desenvolvimento profissional e também pessoal, especialmente para os alunos de cursos de engenharias, que podem ter dificuldades nas relações pessoais, pelas especificidades do curso. Então, a extensão pode proporcionar o contato com a realidade e com as pessoas, "ele pode se relacionar mais com as pessoas, aprender o contexto em que ele está inserido e ser um transformador da realidade" (ENTREVISTADO).

Os integrantes da equipe da Prorec "têm ministrado palestras sobre temas como: inovação, propriedade intelectual, mobilidade estudantil”, entre outros, segundo Relatório de Gestão (UTFPR, 2013, p.368), o que demonstra a preocupação da universidade em trabalhar em rede e de forma aticulada com outros órgãos da comunidade externa.

Em se tratando de parcerias para a realização das ações de extensão comunitárias, podemse destacar os resultados positivos, que envolvem não só a comunidade interna, mas também a externa. Portanto, as transformações que ocorrem nos indivíduos e em seu entorno são benéficas e "capacitam, transformam a comunidade" ao mesmo tempo em que possibilitam aos alunos aprimorar o conhecimento teórico por meio de sua aplicação prática (ENTREVISTADO).

Uma das dificuldades indicadas pelo entrevistado diz respeito à falta de reconhecimento da extensão, pois “a pesquisa é vista como um status para o pesquisador, o ensino é visto como obrigação (atividade-fim) e a extensão é vista como mais uma coisa para fazer", que não reduz a carga horária, então é difícil convencer os que não participam de atividades da extensão a desenvolverem estas.

Mas, conforme o entrevistado, a UTFPR está trabalhando de forma a vencer essa dificuldade, com ações para inclusão da extensão em cada disciplina, ou na maior parte dessas, o que envolve um processo de conscientização dos professores para que identifiquem formas de aplicação prática dos conteúdos de suas disciplinas junto à comunidade. Afirma que "o aluno vai ter a base teórica, um pouco menor, aí ele vai ser levado numa comunidade para aplicar essa base teórica. Ou seja, o ensino vai ser na prática, então ele vai potencializar, vai diminuir a carga horária, porque na prática você aprende muito mais rápido do que na teoria".

Os dados indicaram que um dos desafios em uma universidade multicâmpus é a de se fazer representar institucionalmente, principalmente, nas áreas artísticas, culturais e esportivas. 
Portanto, necessário se faz, propor recomendações para melhoria dos processos e práticas de extensão na UTFPR na consolidação do documento do Plano de Cultura da UTFPR.

Indica-se a continuidade do Programa Institucional de Apoio a Ações de Extensão cujo foco são os Editais de Bolsas de Extensão e de Inovação, que representam um diferencial na UTFPR, pois permitem a participação de alunos e de todos os servidores (professores e administrativos) doutores ou mestres da UTFPR, a submetam seus projetos extencionistas (em geral, somente professores doutores podem participar de editais para fomento com bolsas para seus alunos). Esta disponibilização de recursos para o desenvolvimento de projetos de extensão contribui de forma significativa na realização de ações para a comunidade interna e externa (ARAUJO et al., 1998; CABRAL, 2012; CARBONARI; PEREIRA, 2007; NUNES; SILVA, 2011; SANTOS, 2012).

Embora a pesquisa demonstre que a UTFPR tem cumprido seu papel com uma instituição pública voltada para ações de extensão, necessário se faz reforçar sempre, em todos os documentos e Políticas de Extensão, a indissociabilidade entre ensino, pesquisa e extensão, tendo em vista o cumprimento dos objetivos definidos no Plano Nacional de Extensão Universitária (FORPROEX, 2001), promovendo ações que aproximem a relação universidade-sociedade por meio do saber e fazer, segundo propõe Serrano (2014).

\section{CONSIDERAÇÕES FINAIS}

A partir do objetivo, estruturado em torno da questão de como se desenvolveu e se estruturou a extensão universitária em uma instituição pública, foi possível apresentar uma análise da experiência da extensão na UTFPR. Por meio de análise crítica foi possível levantar os fatores estratégicos que colaboraram na promoção da extensão em todos os câmpus da UTFPR. A pesquisa revelou a importância da extensão cujas ações estão voltadas para a formação integral de sua comunidade

Quanto ao objetivo para apresentar o contexto organizacional das práticas de extensão na UTFPR e sua estrutura multicâmpus, pode-se constatar que todas as ações de extensão, por meio de programas e projetos, estão bem direcionadas em uma pró-reitoria com atividades específicas, devidamente reguladas por documentos internos e com grande representatividade em suas ações extensionistas na universidade e fora dela.

Em relação ao objetivo para identificar os mecanismos utilizados pelos programas, projetos e ações de extensão bem como a articulação entre a extensão, ensino e pesquisa na UTFPR, foi possível constatar que há uma estrutura formal de gestão das ações de extensão, no seu ambiente acadêmico, as quais buscam apoiar e subsidiar os programas, projetos de sua 


\section{A prática extensionista em uma universidade pública federal}

comunidade discente, docente e de técnicos-administrativos, de forma integral e documentada e ainda, buscam promover a integração do tripé ensino-pesquisa-extensão.

Em relação ao objetivo para avaliar a coerência entre a legislação, a demanda regional e o resultado da UTFPR, constatou-se que a instituição mantém documentos regulatórios e mecanismos por meio de indicadores que permitem estimular a interação entre a universidade e a sociedade, desvinculando as ações de extensão de um caráter assistencialista, por meio de ações de abrangência interna e externa.

Em relação ao objetivo para propor recomendações para melhoria dos processos e práticas de extensão na UTFPR, pode-se sugerir práticas que complementam as ações já em desenvolvimento e ainda propor melhorias nas ações que são desafiadoras para a universidade.

A UTFPR apresentou nos dados da pesquisa aplicada os resultados que destacam as ações de extensão, aliando o saber teórico e prático, no processo interdisciplinar da universidade voltada para a sociedade, conforme a literatura abordada, alcançando seu estágio de maturidade após 10 anos de existência. Desta forma, para a comunidade da UTFPR, interna e externa, a dinâmica da extensão, assim como os seus mecanismos de facilitação é de conhecimento e objeto de discussão e destacam o papel da universidade como participante do desenvolvimento regional integrado no Estado do Paraná, evidenciando a integração do ensino-pesquisa-extensão, fortemente associados, na busca da produção e compartilhamento de conhecimento tecnológico e social.

Portanto, esta pesquisa destaca os enfoques citados na literatura, sobre a trajetória da extensão universitária, com mudanças significativas em suas atividades, desde a visão assistencialista, para a aprendizagem pautada no pensamento crítico e o importante papel da universidade como um agente do desenvolvimento, articulando os agentes locais e a superação das restrições tecnológicas, econômicas e sociais das realidades regionais onde está inserida. Estudos acadêmicos discutem a relevância da articulação do tripé ensino-pesquisa-extensão, no entanto, os estudos se detêm às discussões teóricas. Esta pesquisa contribui, portanto, apresentando ações realizadas em uma universidade pública, evidenciando a integração do ensino-pesquisa-extensão, fortemente associados, na busca da produção e compartilhamento de conhecimento tecnológico e social.

Sugere-se, no entanto, a estruturação de novas pesquisas visando identificar como os alunos percebem a extensão dentro de sua formação profissional. Também surge o interesse em verificar como a participação em atividades de extensão tem impactado na formação profissional dos egressos, pela perspectiva da classe empresarial. 


\section{REFERÊNCIAS}

ARAUJO, M.; WIZNIEWSKY, J.G.; TSUKAHARA, R.T.; ARAUJO, L. A prática da indissociabilidade do ensino-pesquisa-extensão na universidade. Rev. Bras. de Agrociência, v.4, no 3, p. 177-182, Set.-Dez.,1998.

BRASIL. Constituição da República Federativa do Brasil. Brasília: Senado Federal, 1988.

CABRAL, N.G. Saberes em extensão universitária: contradições, desafios e desassossegos. 259 p. Tese (Doutorado em Educação) - Universidade Federal do Rio Grande do Sul, Porto Alegre, 2012.

CARBONARI, M.E.E.; PEREIRA, A.C. A extensão universitária no Brasil, do assistencialismo à sustentabilidade. Revista de Educação, v. 10, n. 10, p. 23-28, 2007.

FORPROEX. Fórum de Pró-Reitores de Extensão das Universidades Públicas Brasileiras e SESu/MEC. Plano Nacional de Extensão Universitária. Edição Atualizada. Brasil, 2000/2001. Disponível em: http://www.utfpr.edu.br/estrutura-universitaria/proreitorias/prorec/diretoria-de-extensao/documentos-da-extensao-de-ambito-nacional/planonacional-de-extensao/view. Acesso em: 25 set. 2014.

FRANZ, N.K. Transformative learning in extension staff partnerships: facilitating personal, joint, and organizational change. Journal of Extension, v. 41, n.2, 2003. Disponível em: http://www.joe.org/joe/2003april/a1.php. Acesso em: 02 jun. 2015.

GOULART, A.T. A importância da pesquisa e da extensão na formação do estudante universitário e no desenvolvimento de sua visão crítica. Horizonte, v. 2, n. 4, p. 60-73, 2004.

KING, D.A.; BOEHLJE, M.D. Extension: on the brink of distinction or extinction? Journal of Extension, v. 38, n. 5, p. 14-24, 2000. Disponível em: http://www.joe.org/joe/2000october/comm1.html. Acesso em: 02 jun. 2015.

KING, E. Education revised for a world in transformation. Comparative education, $v .35$, n. 2, p. 109-117, 1999.

MACIEL, L.R. Política Nacional de Extensão: perspectivas para a universidade brasileira. Revista Participação, v. 10, n. 18, p. 15-25, 2010.

NUNES, A.L.P.F.; SILVA, M.B.C. A extensão universitária no ensino superior e a sociedade. Mal-Estar e Sociedade, v. 4, n. 7, p. 119-133, 2011.

OROZCO, M.F. La extensión universitaria y la universidad pública. Reencuentro, n. 39, p. 4754, 2004.

RODRIGUES, R. A extensão universitária como uma práxis. Em Extensão, v. 5, n. 1, 2008.

SAMPAIO, R.M.; LANIADO, R.N. Uma experiência de mudança da gestão universitária: o percurso ambivalente entre proposições e realizações. Revista de Administração Pública, v. 4, n. 1, p. 151-174, jan./fev. 2009. 
A prática extensionista em uma universidade pública federal

SANTOS, M.P. Extensão universitária: espaço de aprendizagem profissional e suas relações com o ensino e a pesquisa na educação superior. Revista Conexão UEPG, v. 8, n. 2, p. 154-163, 2012.

SERRANO, R.M.S.M. Conceitos de extensão universitária: um diálogo com Paulo Freire. Disponível

em: http://xa.yimg.com/kq/groups/20876648/372422751/name/conceitos_de_extensao_universita ria.pdf. Acesso em: 24 out. 2014.

SILVA, O.D. O que é extensão universitária? Rev Integ Ens Pesq Ext. v. 3, n. 9, p. 148-9, mai. 1997. Disponível em: http://ecientificocultural.com/edu_sup.htm. Acesso em: 28 out. 2015.

UTFPR. Universidade Tecnológica Federal do Paraná. Guia de Extensão. 2012. Disponível em: https://issuu.com/dirext/docs/guia_de_extens_o_da_utfpr?viewMode $=$ doublePage\&e $=611493$ 7/2624100. Acesso em: 15 abr. 2015.

Institucional. Disponível em: http://www.utfpr.edu.br. Acesso em: 10 mar. 2015.

Relatórios de Gestão. Disponível em: http://www.utfpr.edu.br/estruturauniversitaria/diretorias-de-gestao/diretoria-de-gestao-da-avaliacao-institucional/relatorios-degestao/. Acesso em: 15 abr. 2015.

YIN, R.K. Estudo de caso: planejamento e métodos. São Paulo: Bookman, 2015.

Recebido em: 19/08/2017

Aceito em: 06/07/2018 